\title{
Pengelolaan Pemangkasan Tanaman Teh (Camellia sinensis (L.) O. Kuntze) di Wonosobo
}

\section{Pruning Management of Tea (Camellia sinensis (L.) O. Kuntze) at Wonosobo}

\author{
Naelatur Rohmah dan Ade Wachjar* \\ Departemen Agronomi dan Hortikultura, Fakultas Pertanian, Institut Pertanian Bogor \\ (Bogor Agricultural University), Jl. Meranti, Kampus IPB Darmaga, Bogor 16680, Indonesia \\ Telp.\&Faks. 62-251-8629353 e-mail agronipb@indo.net.id \\ *Penulis untuk korespondensi: wachjarade@ yahoo.co.id \\ Disetujui 7 Januari 2015/ Publish online 15 januari 2015
}

\begin{abstract}
This activity was aimed to learn the technical aspects and management of producing wet tea into dried tea. It is also aimed to analyze deeply the technical and management aspects of pruning applied in the field. The research was conducted at Wonosobo, Central Java for four months from February to June 2013. Data collection activities are used direct methods to obtain primery data and indirect methods to obtain secondary data. The purpose of pruning is to increase the productivity of tea because it can stimulate the growth of some new shoots so it can produce the shoots in large quantities. The tea pruning activity was good with the damage level of the branches which were low. Moreover, it was not also affected by the age and the work duration of the workers.
\end{abstract}

Keywords: pruning, tea plant, technique and management

\begin{abstract}
ABSTRAK
Kegiatan bertujuan mempelajari pengelolaan produksi teh basah hingga menghasilkan teh kering. Kegiatan penelitian juga bertujuan mempelajari secara mendalam serta menganalisis aspek teknis dan pengelolaan pemangkasan yang diterapkan di lapangan. Penelitian dilaksanakan selama empat bulan mulai dari bulan Februari hingga Juni 2013 di Wonosobo, Jawa Tengah. Pengamatan dan pengumpulan data dilakukan secara langsung untuk memperoleh data primer dan tidak langsung untuk memperoleh data sekunder. Secara umum pemangkasan bertujuan untuk meningkatkan produktivitas teh karena pemangkasan dapat merangsang pertumbuhan tunas baru sehingga mampu menghasilkan pucuk yang lebih banyak. Unit Pelaksanaan pemangkasan sudah baik dengan tingkat kerusakan cabang yang tidak terlalu tinggi serta tidak dipengaruhi oleh usia ataupun lama masa kerja dari tenaga pemangkas.
\end{abstract}

Kata kunci: pemangkasan, tanaman teh, teknik dan pengelolaan 


\section{PENDAHULUAN}

Teh sebagai salah satu komoditas perkebunan yang telah lama diusahakan di Indonesia memiliki peranan yang cukup penting. Teh termasuk ke dalam komoditas ekspor sub sektor perkebunan sebagai sumber devisa negara. Usaha perkebunan teh juga mampu menyerap tenaga kerja sekitar 101698 orang pada tahun 2012 (Ditjenbun 2012). Menurut Herawati dan Nurbaeti (2004), dalam bidang kesehatan teh dikenal sebagai tanaman penyegar yang baik untuk kesehatan tubuh manusia. Keunggulan teh Indonesia diantaranya mengandung katekin 1.34 kali lebih tinggi dari pada teh dari negara lain.

Luas areal perkebunan teh di Indonesia pada tahun 2008 adalah 127712 ha dengan produksi 153971 ton dan total volume ekspor teh Indonesia mencapai 96209 ton dengan nilai ekspor US\$ 158.958 juta. Pada tahun 2011 terjadi penurunan, baik pada luas areal perkebunan teh Indonesia menjadi 123938 ha, produksi teh Indonesia menjadi 150776 ton, maupun total volume ekspor teh Indonesia menjadi 75450 ton dengan nilai ekspor US\$166.717 juta (Ditjenbun 2012).

Penurunan produksi teh Indonesia dapat disebabkan oleh beberapa faktor seperti kondisi iklim mikro yang kurang mendukung untuk pertumbuhan tanaman teh, serangan hama penyakit (Widayat dan Johan 2006), konversi lahan perkebunan teh menjadi lahan pertanian hortikultura, serta faktor pengelolaan tanaman yang belum memadai, salah satunya dalam pengelolaan pemangkasan.

Bagian yang dapat dipanen dan bernilai ekonomi dari tanaman teh adalah pucuk atau daun teh muda. Oleh karena itu keadaan tanaman teh sangat mempengaruhi produksi, baik jumlah maupun kualitas pucuk yang dihasilkan (Junaedi dan Susanto 1996). Pucuk dan daun teh muda baik mutu maupun jumlahnya dapat ditingkatkan melalui kegiatan pemangkasan. Hal ini disebabkan pemangkasan dapat merangsang pertumbuhan tunas baru sehingga mampu menghasilkan pucuk yang lebih banyak.

Pemangkasan tidak hanya mampu meningkatkan produktivitas tanaman, tetapi juga bertujuan untuk memudahkan pemetikan, mempertahankan pertumbuhan tanaman dalam fase vegetatif serta membuang cabang-cabang yang tidak dikehendaki yang dapat menghambat pertumbuhan tunas baru (Dalimoenthe dan Rachmiati 2009). Faktor-faktor yang dapat menentukan keberhasilan pemangkasan antara lain jenis pangkasan, waktu pemangkasan, daur pangkasan, cara pemangkasan dan tingkat 80 kemahiran tenaga pemangkas (PPTK 2006). Tujuan dari penelitian untuk mempelajari secara mendalam serta menganalisis aspek teknis dan pengelolaan pemangkasan yang diterapkan di lapangan sehingga mampu mengidentifikasi dan memecahkan masalah yang terkait dengan pengelolaan pemangkasan tanaman teh.

\section{BAHAN DAN METODE}

Kegiatan penelitian dilaksanakan di Dusun Bedakah, Desa Tlogomulyo, Kecamatan Kertek, Kabupaten Wonosobo, Provinsi Jawa Tengah dengan ketinggian tempat 1200 sampai dengan $1950 \mathrm{~m}$ dpl. pada bulan Februari sampai Juni 2013. Pengamatan dan pengumpulan data secara langsung untuk memperoleh data primer dan tidak langsung untuk memperoleh data sekunder. Data primer diperoleh secara langsung dengan melakukan pengamatan, bekerja langsung di lapangan, wawancara dan diskusi dengan pimpinan, staf karyawan dan pekerja kebun. Data primer yang diambil di lapangan difokuskan pada kegiatan pemangkasan.

Pengumpulan data sekunder dilakukan dengan mempelajari laporan manajemen kebun, arsip kebun, dan studi pustaka. Data yang dikumpulkan meliputi keadaan umum perkebunan terdiri atas sejarah perkebunan, letak administratif, keadaan iklim, tanah dan topografi, luas areal konsesi (HGU) dan tata guna lahan, keadaan tanaman dan produksi, struktur organisasi dan ketenagakerjaan, dan peta lokasi.

Pengamatan lapangan dilakukan di tiga blok terhadap 15 tanaman contoh untuk setiap bloknya. Pengamatan dilakukan dalam tiga tahapan yaitu sebelum pemangkasan, saat pemangkasan dan setelah pemangkasan. Variabel pengamatan yang diamati sebelum pemangkasan meliputi : (1) tinggi bidang petik (diukur dari permukaan tanah sampai puncak bidang petik), (2) diameter bidang petik (mengukur diameter bidang petik pada keempat arah yaitu timur - barat dan utara - selatan kemudian diambil rata-rata keduanya), dan (3) persentase pucuk burung (menghitung jumlah pucuk burung dan peko dengan menggunakan lingkaran dari bambu berdiameter $75 \mathrm{~cm}$ ).

Variabel pengamatan yang diamati saat pemangkasan meliputi : (1) tinggi bidang pangkas (diukur dari permukaan tanah sampai luka bekas pangkasan), (2) persentase kerusakan cabang akibat pemangkasan (menghitung jumlah cabang yang rusak atau pecah akibat pemangkasan yang dilakukan oleh 10 tenaga pemangkas berdasarkan klasifikasi tingkat usia dan lamanya masa kerja), 
(3) kebutuhan tenaga pemangkas (menghitung maupun wawancara dengan pembimbing), (4) waktu pemangkasan (membandingkan kesesuaian waktu pelaksanaan pemangkasan di lapangan dengan rencana yang telah dibuat), (5) luas areal pangkasan dan gilir pangkas (wawancara dengan pembimbing lapangan dan mempelajari laporan tahunan), serta (6) jenis pangkasan dan alat pangkas (pengamatan langsung dan wawancara dengan pembimbing lapangan).

Pengamatan setelah pemangkasan dilakukan terhadap tinggi tunas dengan cara mengukur tinggi 10 ranting tunas pada 15 tanaman contoh mulai dari pangkal tunas sampai titik tumbuh. Pengamatan dilakukan setiap minggu mulai lima minggu hingga delapan minggu setelah pemangkasan (5 - $8 \mathrm{MSP}$ ).

Pengolahan data dilakukan dengan menggunakan rataan, persentase dan uji t-student kemudian hasilnya dibandingkan dengan standar kerja setiap kegiatan yang berlaku di perusahaan. Uji $t$-student pada taraf $5 \%$ digunakan untuk mengetahui persentase kerusakan cabang akibat langsung jumlah tenaga pemangkas riil di kebun pemangkasan berdasarkan keterampilan pemangkas.

\section{HASIL DAN PEMBAHASAN}

\section{Tinggi dan Diameter Bidang Petik}

Pemangkasan biasanya dilakukan saat tinggi bidang petik mencapai $120 \mathrm{~cm}$. Menurut Sukasman (1988), tinggi maksimal bidang petik yang sesuai bagi pemetik yaitu $120 \mathrm{~cm}$ karena ukuran rata-rata tinggi pemetik di Indonesia adalah $155-165 \mathrm{~cm}$. Bidang petik yang terlalu tinggi dan diameter tajuk yang terlalu lebar dapat menyulitkan tenaga pemetik dalam kegiatan pemetikan sehingga dapat menurunkan kapasitas pemetik. Hasil pengamatan yang dilakukan terhadap tinggi dan diameter bidang petik sebelum pemangkasan menunjukkan bahwa rata-rata bidang petik mempunyai ketinggian $105.62 \mathrm{~cm}$ dengan diameter sebesar $106.7 \mathrm{~cm}$ (Tabel 1).

Tabel 1. Tinggi dan diameter bidang petik sebelum pemangkasan

\begin{tabular}{lrlcccc}
\hline Blok & $\begin{array}{c}\text { No. } \\
\text { Kebun }\end{array}$ & Jenis tanaman & $\begin{array}{c}\text { Umur pangkas } \\
\text { (tahun) }\end{array}$ & $\begin{array}{c}\text { Jumlah tanaman contoh } \\
\text { (tanaman) }\end{array}$ & $\begin{array}{c}\text { Tinggi } \\
\text { bidang petik }\end{array}$ & $\begin{array}{c}\text { Diameter } \\
\text { bidang petik }\end{array}$ \\
\hline Rinjani & 8 & Gambung 4 & & & $\ldots \ldots \ldots \ldots(\mathrm{cm}) \ldots \ldots \ldots \ldots$ \\
Bismo & 11 & TRI 2025 & 5 & 15 & 100.47 & 102.93 \\
Argopuro & 4 & Seedling & 6 & 15 & 103.87 & 82.40 \\
\hline Rata-rata & & & & 15 & 112.53 & 134.77 \\
\hline
\end{tabular}

Rata-rata tinggi bidang petik dari hasil pengamatan belum memenuhi syarat untuk dipangkas, tetapi diameter bidang petik cukup lebar bila dibandingkan dengan jarak tanam 120 $\mathrm{cm} \times 75 \mathrm{~cm}$ sehingga penutupan tajuk tanaman cukup rapat. Faktor lain yang menyebabkan bidang petik tidak terlalu tinggi yaitu keterampilan pemetik yang kurang dalam penggunaan gunting petik dan mesin petik sehingga pemetikan sering kali dilakukan di bawah bidang petik (ngrogoh).

\section{Persentase Pucuk Burung}

Hasil pengamatan menunjukkan bahwa Blok Rinjani, Bismo dan Argopuro telah memenuhi kriteria untuk dipangkas dengan rata-rata persentase pucuk burung mencapai $82 \%$ (Tabel 2). Tobroni (1990) menyatakan semakin tua umur pangkas tanaman teh, maka jumlah atau persentase pucuk peko yang dihasilkan semakin rendah, sedangkan jumlah atau persentase pucuk burung semakin meningkat.

Tabel 2. Persentase pucuk burung sebelum pemangkasan

\begin{tabular}{lclccc}
\hline Blok & $\begin{array}{c}\text { No. } \\
\text { kebun }\end{array}$ & Jenis tanaman & $\begin{array}{c}\text { Umur pangkas } \\
\text { (tahun) }\end{array}$ & $\begin{array}{c}\text { Jumlah tanaman } \\
\text { contoh (tanaman) }\end{array}$ & $\begin{array}{c}\text { Persentase pucuk burung } \\
(\%)\end{array}$ \\
\hline Rinjani & 8 & Gambung 4 & 5 & 15 & 87 \\
Bismo & 11 & TRI 2025 & 5 & 15 & 79 \\
Argopuro & 4 & Seedling & 6 & 15 & 80 \\
\hline Rata-rata & \multicolumn{7}{r}{} & & & 82 \\
\hline
\end{tabular}


Tingkat Produktivitas

Keputusan suatu nomor kebun untuk dipangkas umumnya karena tingkat produktivitas kering semakin menurun. Blok Argopuro mencapai tingkat produktivitas tertinggi pada umur pangkas ketiga, sedangkan Blok Rinjani dan Blok Bismo pada umur pangkas keempat. Selanjutnya ketiga blok mengalami penurunan produktivitas pada umur pangkas berikutnya sehingga diambil kebijakan untuk dilaksanakan pemangkasan (Gambar 1).

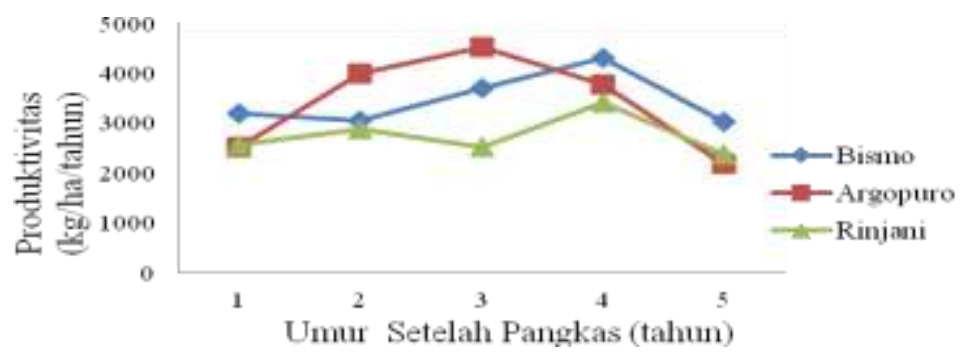

Gambar 1. Produktivitas pucuk tahun 2012 berdasarkan tahun pangkas

\begin{abstract}
Menurut Dalimoenthe dan Rachmiati (2009), umur pangkas yang meningkat berhubungan dengan umur jaringan yang semakin tua yang akan mempengaruhi kemampuan pembelahan sel sehingga produksi pucuk berkurang. Oleh karena itu tanaman perlu dipangkas untuk mempermuda umur jaringan. Selain itu menurut Sukasman (1988), semakin tua umur pangkas maka bidang petik semakin luas dan jumlah pucuk yang dihasilkan semakin banyak, tetapi ukuran pucuk semakin kecil dan bobot menjadi ringan akibat adanya persaingan antar pucuk dalam memperoleh hasil fotosintat.
\end{abstract}

\section{Tinggi Bidang Pangkas}

Standar tinggi pangkasan produksi yang ditetapkan adalah 50 - $55 \mathrm{~cm}$. Pangkasan produksi pertama dilakukan pada ketinggian $45 \mathrm{~cm}$ dari permukaan tanah dan setiap pangkasan berikutnya dinaikkan $5 \mathrm{~cm}$ dari luka pangkas sebelumnya hingga mencapai tinggi $55 \mathrm{~cm}$. Setelah mencapai ketinggian $55 \mathrm{~cm}$, maka tinggi pangkasan diturunkan kembali pada ketinggian pangkasan 50 $\mathrm{cm}$. Hasil pengamatan menunjukkan bahwa ketinggian pangkasan pada setiap blok masih mengikuti standar tinggi pangkasan yang berlaku (Tabel 3).

Tabel 3. Tinggi bidang pangkas saat pemangkasan

\begin{tabular}{|c|c|c|c|c|c|c|}
\hline \multirow{2}{*}{ Blok } & \multirow{2}{*}{$\begin{array}{l}\text { No. } \\
\text { Kebun }\end{array}$} & \multirow{2}{*}{$\begin{array}{l}\text { Tahun } \\
\text { tanam }\end{array}$} & \multirow{2}{*}{$\begin{array}{l}\text { Umur pangkas } \\
\text { (tahun) }\end{array}$} & \multirow{2}{*}{$\begin{array}{l}\text { Jumlah tanaman } \\
\text { contoh (tanaman) }\end{array}$} & \multicolumn{2}{|c|}{ Tinggi bidang pangkas } \\
\hline & & & & & Standar & Realisasi \\
\hline & & & & & \multicolumn{2}{|c|}{$\ldots \ldots .(\mathrm{cm}) \ldots \ldots \ldots \ldots$} \\
\hline Rinjani & 8 & 1998 & 5 & 15 & $50-55$ & 50.93 \\
\hline Bismo & 11 & 1986 & 5 & 15 & $50-55$ & 50.27 \\
\hline Argopuro & 4 & 1938 & 6 & 15 & $50-55$ & 53.87 \\
\hline Rata-rata & & & & & $50-55$ & 51.69 \\
\hline
\end{tabular}

Rata-rata tinggi bidang pangkas dari hasil pengamatan yaitu $51.69 \mathrm{~cm}$ (Tabel 3). Menurut Johan (2005), tinggi pangkasan $50 \mathrm{~cm}$ dapat merangsang pertumbuhan tunas lebih cepat dan dapat meningkatkan hasil pucuk teh. PPTK (2006) menyatakan bahwa tinggi pangkasan bagi kebun produktif (TM) berkisar $\quad 40-70 \mathrm{~cm}$. Tinggi pangkasan yang kurang dari $40 \mathrm{~cm}$ akan menyebabkan percabangan yang terbentuk menjadi terlalu rendah sehingga menyulitkan pemetik saat pemetikan, sedangkan tinggi pangkasan yang lebih dari $70 \mathrm{~cm}$ akan menumbuhkan lebih banyak tunas dalam keadaan dorman dan berukuran kecil.

\section{Persentase Kerusakan Cabang Akibat Pemangkasan}

Tenaga pemangkas merupakan salah satu faktor yang mempengaruhi tingkat kerusakan cabang akibat pemangkasan disamping faktor ketajaman alat. Hasil uji $t$-student menunjukkan bahwa perbedaan usia pemangkas tidak berpengaruh terhadap besarnya kerusakan cabang (Tabel 4). Hasil uji t-student terhadap persentase kerusakan 
cabang akibat pemangkasan berdasarkan klasifikasi lamanya masa kerja pemangkas juga menunjukkan bahwa perbedaan lamanya masa kerja tidak berpengaruh terhadap besarnya kerusakan cabang (Tabel 4). Kerusakan cabang yang terjadi di kebun dari hasil pengamatan penulis disebabkan tenaga pemangkas lebih mengejar kuantitas daripada kualitas pangkasan serta kurangnya pengawasan dari pembimbing pemeliharaan.

Tabel 4. Persentase kerusakan cabang

\begin{tabular}{cccc}
\hline Usia tenaga & \multicolumn{2}{c}{ Jumlah } & $\begin{array}{c}\% \\
\text { pemangkas (tahun) }\end{array}$ \\
\cline { 2 - 3 } & (orang) & (tanaman) & Kerusakan \\
\hline$\leq 50$ & 5 & 25 & 5.447 \\
$>50$ & 5 & 25 & 6.917 \\
\hline Lama masa kerja & & & \\
(tahun) & & & \\
\hline$<20$ & 5 & 25 & 5.689 \\
$\geq 20$ & 5 & 25 & 6.623 \\
\hline
\end{tabular}

\section{Kebutuhan Tenaga Pemangkas}

Tenaga pemangkas di Unit Perkebunan Bedakah merupakan tenaga karyawan harian lepas atau musiman dengan sistem upah borongan. Upah dibayarkan berdasarkan jumlah patok yang diperoleh. Upah tenaga pangkas berkisar Rp 15 000,00 - Rp 20 000,00 per patok. Kebutuhan tenaga pemangkas di tiga blok Unit Perkebunan Bedakah tercantum pada Tabel 5. Hasil pengamatan menunjukkan bahwa jumlah tenaga kerja di lapangan lebih sedikit dibandingkan jumlah tenaga kerja berdasarkan perhitungan (Tabel 6). Kekurangan tenaga kerja khususnya tenaga pemangkas menjadi masalah bagi Unit Perkebunan Bedakah. Penduduk di sekitar perkebunan mulai beralih pada kegiatan pertanian sehingga pihak perkebunan kesulitan untuk mendapatkan tenaga kerja terutama saat musim panen hasil pertanian.

Tabel 5. Kebutuhan tenaga pemangkas di tiga blok

\begin{tabular}{|c|c|c|c|c|c|c|c|}
\hline \multirow[t]{2}{*}{ Blok } & \multirow[t]{2}{*}{ Luas areal (ha) } & \multirow{2}{*}{$\begin{array}{c}\text { Waktu } \\
\text { penyelesaian } \\
\text { (bulan) }\end{array}$} & \multirow{2}{*}{$\begin{array}{l}\text { Luas areal pangkas } \\
\text { (ha/hari) }\end{array}$} & \multicolumn{2}{|c|}{ Jumlah pemangkas (orang) } & \multicolumn{2}{|c|}{$\begin{array}{c}\text { Kapasitas pemangkas } \\
\text { (ha/HK) }\end{array}$} \\
\hline & & & & Teori $^{\mathrm{a}}$ & Riil $^{b}$ & Standar & Riil \\
\hline Rinjani & 3.81 & 1.0 & 0.15 & 3.81 & 2 & 0.04 & 0.08 \\
\hline Bismo & 8.85 & 2.0 & 0.18 & 4.43 & 3 & 0.04 & 0.06 \\
\hline Argopuro & 2.40 & 0.5 & 0.19 & 4.80 & 4 & 0.04 & 0.05 \\
\hline Jumlah & 15.06 & 3.50 & 0.52 & 13.04 & 9 & 0.12 & 0.18 \\
\hline Rata-rata & 5.02 & 1.17 & 0.17 & 4.35 & 3 & 0.04 & 0.06 \\
\hline
\end{tabular}

aJumlah tenaga kerja berdasarkan perhitungan; ${ }^{\mathrm{b}}$ Laporan harian pembimbing pemeliharaan (Mei, 2013)

Pelaksanaan pemangkasan dibagi dalam dua semester dengan persentase luas areal pangkasan pada semester I lebih besar dibandingkan persentase luas areal pangkasan pada semester II. Persentase luas areal yang dipangkas pada semester I sebesar $60 \%$ dari total luas areal pangkas dalam setahun, sedangkan semester II dipangkas sebesar $40 \%$ dari total luas areal pangkas dalam setahun. Pertimbangan dilakukannya pangkasan yang lebih luas pada semester I dibandingkan semester II adalah menghindari kematian tanaman akibat serangan hama dan penyakit terutama cacar daun teh.

Realisasi luas areal pangkas tahun 2012 menunjukkan bahwa persentase luas areal yang dipangkas pada semester I hanya sebesar $53.03 \%$ dari total luas areal yang dipangkas dan semester II dilaksanakan dengan persentase luas areal pangkasan $46.97 \%$ total luas areal yang dipangkas (Tabel 7).
Tabel 7. Realisasi luas areal pangkasan tahun 2012

\begin{tabular}{lrr}
\hline Blok & $\begin{array}{c}\text { Luas } \\
\text { (ha) }\end{array}$ & $\begin{array}{c}\text { Luas Areal Pangkas } \\
(\%)\end{array}$ \\
\hline Muria & 3.78 & 8.12 \\
Kembang & 2.68 & 5.75 \\
Bismo & 7.72 & 16.57 \\
Argopuro & 2.71 & 5.82 \\
Rinjani & 1.65 & 3.54 \\
Mandala & 6.16 & 13.22 \\
\hline Semester I & 24.70 & 53.03 \\
\hline Bismo & 4.00 & 8.59 \\
Muria & 8.24 & 17.69 \\
Mandala & 3.57 & 7.66 \\
Argopuro & 3.13 & 6.72 \\
Rinjani & 0.73 & 1.57 \\
Kembang & 2.21 & 4.74 \\
\hline Semester II & 21.88 & \\
\hline Total luas Pangkasan & 46.58 & 100.00 \\
(ha) & \multicolumn{2}{c}{} \\
\hline
\end{tabular}

Perbedaan realisasi dengan rencana luas areal pangkasan disebabkan oleh kurangnya ketersediaan tenaga pemangkas saat pemangkasan. Tenaga pemangkas yang tidak memadai saat pemangkasan menyebabkan tidak 
tercapainya target luas areal yang harus dipangkas setiap bulannya, akibatnya waktu pemangkasan menjadi tertunda sehingga persentase luas areal yang dipangkas berkurang. Faktor lain yang mempengaruhi yaitu kondisi mikroklimat yang tidak mendukung dan kebijakan kebun.

\section{Waktu Pemangkasan}

Kegiatan pemangkasan di Unit Perkebunan Bedakah direncanakan dalam dua semester. Semester I direncanakan pada bulan Februari sampai April (akhir musin hujan), sedangkan semester II direncanakan pada bulan Oktober sampai November (awal musim hujan). Menurut Suwardi (1991), pemangkasan dapat dilaksanakan pada bulan Maret - Juni dan bulan Oktober - November.

Pemilihan waktu pemangkasan pada bulan-bulan tersebut didasarkan pada kondisi mikroklimat (tanah dan lingkungan) yang masih cukup lembab serta tidak terlalu terik. Menurut Effendi et al. (2012), kondisi iklim mikro yang masih cukup lembab dan tidak terlalu terik dapat menjaga kesehatan tanaman sehingga kecepatan penutupan (recovery) daun lebih cepat. Realisasi waktu pemangkasan di Unit Perkebunan Bedakah tahun 2012 tercantum pada Tabel 8.

Data realisasi waktu pemangkasan pada tahun 2012 menunjukkan bahwa kegiatan pemangkasan pada semester I dilaksanakan pada bulan Januari sampai dengan bulan Juni, sedangkan semester II dilaksanakan pada bulan
November sampai dengan Desember (Tabel 8). Pelaksanaan waktu pemangkasan di lapangan yang melebihi rencana disebabkan karena keadaan iklim, suhu dan kelembaban dianggap masih aman untuk pelaksanaan pemangkasan, selain karena faktor ketersediaan tenaga kerja yang tidak memadai saat akan dilaksanakan pemangkasan.

Tabel 8. Realisasi waktu pemangkasan

\begin{tabular}{|c|c|c|}
\hline Blok & Rencana & Realisasi \\
\hline \multicolumn{3}{|l|}{ Semester I } \\
\hline Muria & Feb, Maret, April & $\begin{array}{l}\text { Jan, Feb, Maret, } \\
\text { April }\end{array}$ \\
\hline Kembang & Feb, Maret, April & $\begin{array}{l}\text { Jan, Feb, Maret, } \\
\text { April, Mei }\end{array}$ \\
\hline Bismo & Feb, Maret, April & Jan, Feb, Mei, Juli \\
\hline Argopuro & Feb, Maret, April & Mar, April,Mei \\
\hline Rinjani & Feb, Maret, April & April dan Mei \\
\hline Mandala & Feb, Maret, April & Mei, Juni \\
\hline \multicolumn{3}{|l|}{ Semester II } \\
\hline Bismo & Okt, Nov & Nov dan Des \\
\hline Muria & Okt, Nov & Nov dan Des \\
\hline Mandala & Okt, Nov & Nov dan Des \\
\hline Argopuro & Okt, Nov & Nov dan Des \\
\hline Rinjani & Okt, Nov & Desember \\
\hline Kembang & Okt, Nov & Desember \\
\hline
\end{tabular}

\section{Gilir Pangkas}

Gilir pangkas merupakan jangka waktu antara pemangkasan sebelumnya dengan pangkasan berikutnya pada satu blok yang sama. Gilir pangkas dari tiga blok di Unit Perkebunan Bedakah tercantum pada Tabel 9.

Tabel 9. Gilir pangkas di Blok Bismo, Rinjani dan Argopuro tahun 2013

\begin{tabular}{|c|c|c|c|c|c|c|c|}
\hline \multirow{2}{*}{ Blok } & \multirow{2}{*}{$\begin{array}{l}\text { No. } \\
\text { kebun }\end{array}$} & \multirow{2}{*}{$\begin{array}{l}\text { Luas areal } \\
\text { (ha) }\end{array}$} & \multirow{2}{*}{$\begin{array}{l}\text { Tinggi tempat } \\
(\mathrm{m} \mathrm{dpl})\end{array}$} & \multirow{2}{*}{$\begin{array}{c}\text { Waktu pangkas } \\
\text { sebelumnya }\end{array}$} & \multicolumn{2}{|c|}{ Waktu pangkas berikutnya } & \multirow{2}{*}{$\begin{array}{l}\text { Gilir pangkas } \\
\text { (tahun) }\end{array}$} \\
\hline & & & & & Rencana & Realisasi & \\
\hline \multirow{2}{*}{ Rinjani } & 2 & 2.92 & $1227-1300$ & Maret 2007 & Maret 2013 & April 2013 & 6 \\
\hline & 8 & 1.66 & & Feb 2008 & Feb 2013 & Feb 2013 & 5 \\
\hline \multirow{2}{*}{ Bismo } & 7 & 6.06 & $1325-1353$ & Feb 2009 & April 2013 & April 2013 & 4 \\
\hline & 11 & 2.79 & & Feb 2008 & Januari 2013 & Januari 2013 & 5 \\
\hline Argopuro & 4 & 2.40 & $1306-1420$ & Maret 2007 & Januari 2013 & Januari 2013 & 6 \\
\hline
\end{tabular}

Unit Perkebunan Bedakah berada terletak ketinggian 1200 - $1950 \mathrm{~m}$ dpl yang termasuk ke dalam dataran tinggi sehingga memiliki gilir pangkas 4 tahun. Hasil pengamatan menunjukkan bahwa pemangkasan di Blok Bismo, Rinjani dan Argopuro dilaksanakan pada umur pangkas ke 5 dan 6 (Tabel 9). Realisasi pemangkasan yang melebihi gilir pangkas 4 tahun disebabkan oleh adanya pertimbangan produksi bahwa produktivitas nomor kebun tersebut masih tinggi sehingga tanaman teh masih menguntungkan secara ekonomis. Selain itu, pada tahun 2010 terjadi penundaan pelaksanaan pemangkasan untuk seluruh blok di Unit Perkebunan Bedakah karena adanya program Indikator Kinerja Blok (IKB 01) dari PPTK (Pusat Penelitian Teh dan Kina) Gambung.

\section{Jenis Pangkasan}

Jenis pangkasan yang diterapkan adalah jenis pangkasan bersih. Menurut Sukasman (1988), pada pangkasan bersih akan mengakibatkan sinar matahari dapat menembus bagian bawah tanaman sehingga dapat 
menstimulir tumbuhnya tunas bagian bawah yang memiliki dormansi lebih kuat.

Jenis pangkasan bersih dilakukan dengan cara memotong semua cabang dan ranting beserta daun pada tanaman teh dengan bidang pangkas rata, tetapi bagian tengah tanaman dipotong lebih rendah dibandingkan bagian pinggirnya (ngemangkok). Pangkasan dengan sistem mangkok bertujuan agar pertumbuhan tunas seragam dan tidak ada tunas yang terhambat pertumbuhannya. Sriyadi (2009) menyatakan bahwa pertumbuhan tunas pada perdu teh yang paling kuat terdapat pada bagian pusat atau tengah dan semakin ke tepi akan semakin lemah sehingga pertumbuhan tunas yang terdapat pada bagian tepi akan tertekan karena persaiangan energi yang mengarah ke atas (dominance apical).

\section{Alat Pangkas}

Menurut Setyamidjaja (2000), cabang atau ranting yang yang dipotong berukuran lebih kecil dari ibu jari (diameter kurang dari $2 \mathrm{~cm}$ ) digunakan gaet pangkas, sedangkan untuk cabang atau ranting yang berukuran lebih besar (diameter lebih dari 2 $\mathrm{cm}$ ) digunakan gergaji pangkas. Cabang atau ranting yang dipotong dengan ketinggian pangkasan $50-55 \mathrm{~cm}$ merupakan cabang yang berdiameter kurang dari $2 \mathrm{~cm}$ (lebih kecil dari ibu jari) sehingga pemakaian sabit pangkas sebagai alat pangkas dianggap cukup efektif.
Pemangkasan menggunakan mesin pangkas pernah dilakukan, tetapi hasilnya kurang efektif pada cabang yang berdiameter lebar karena menyebabkan cabang pecah dan rusak.

Pengamatan pertumbuhan tunas bertujuan untuk mengamati kecepatan pertumbuhan tunas setiap minggunya sehingga dapat diketahui waktu pelaksanaan pemetikan jendangan. Hasil pengamatan menunjukkan bahwa pertumbuhan tunas dari klon Gambung 4 dan TRI 2025 lebih cepat dibandingkan tanaman asal seedling (Gambar 2).

Perbedaan kecepatan pertumbuhan tunas dari masing-masing blok dipengaruhi oleh jenis tanaman yang berbeda. Sriyadi (2009) menyatakan bahwa kecepatan pertumbuhan tunas setelah pangkas dipengaruhi oleh kesehatan tanaman terutama cadangan karbohidrat dan kemampuan genotip klon dalam mengubah karbohidrat menjadi energi untuk membentuk tunas baru. Tanaman seedling merupakan jenis tanaman berumur tua sehingga kondisi kesehatan tanaman kurang baik bila dibandingkan dengan tanaman dari jenis klon yang berumur muda. Menurut PPTK (2006), kecepatan pertumbuhan tunas baru ditentukan oleh letak primordial (mata tunas) pada kulit cabang. Primordia yang terletak pada bagian kulit lebih muda akan lebih cepat merangsang pertumbuhan tunas baru dari pada bagian kulit yang lebih tua.

\section{Pertumbuhan Tunas Setelah Pemangkasan}

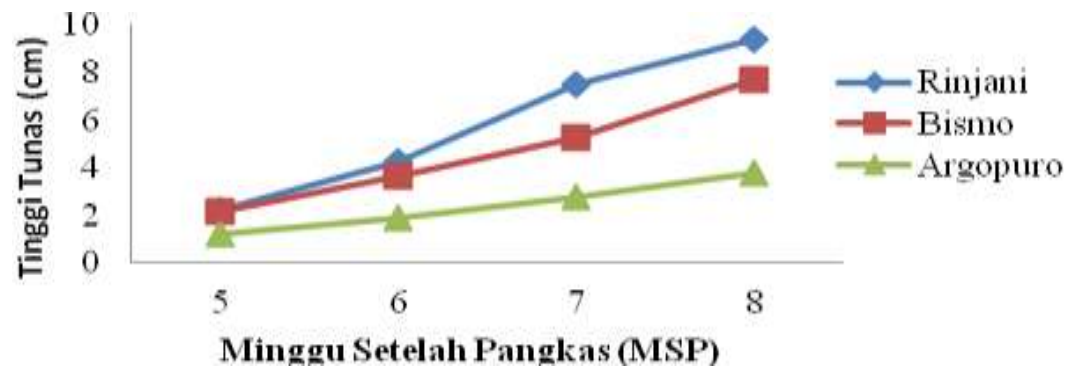

Gambar 2. Pertumbuhan tinggi tunas setelah pemangkasan

\section{KESIMPULAN}

Pelaksanaan pemangkasan sudah baik dengan tingkat kerusakan cabang yang tidak terlalu tinggi dan tidak dipengaruhi usia maupun lama masa kerja dari tenaga pemangkas. Jenis pangkasan yang ditetapkan adalah pangkasan bersih pada ketinggian $50-55 \mathrm{~cm}$ dengan gilir pangkas 4 tahun, tetapi terdapat beberapa nomor kebun yang memiliki gilir pangkas lebih dari 4 tahun. Salah satu permasalahan yang ditemukan di Unit Perkebunan Bedakah adalah kurangnya tenaga kerja karena masyarakat di sekitar perkebunan mulai beralih ke sektor pertanian. Pemakaian mesin pangkas perlu diterapkan kembali untuk mengatasi masalah kekurangan tenaga pemangkas. 


\section{DAFTAR PUSTAKA}

Dalimoenthe, S.L., Rachmiati, Y. 2009. Pengaruh penentuan saat pemangkasan dan pemupukan untuk mempercepat pemulihan pertumbuhan tanaman saat menghadapi perubahan iklim. Jurnal Penelitian Teh dan Kina. 12(3):67-77.

[Ditjenbun] Direktorat Jenderal Perkebunan. 2012. Statistik Perkebunan Indonesia 2011 - 2013 : Teh. Jakarta (ID): Ditjenbun.

Effendi, D.E., Syakir, M., Yusro, M., Wiratno. 2012. Budidaya dan Pasca Panen Teh. Bogor (ID): Pusat Penelitian dan Pengembangan Perkebunan.

Herawati, H., Nurbaeti, B. 2004. Nilai fungsional beberapa komponen aktif yang terkandung dalam teh. Di dalam: Rusastra, I.W., Muharam, A., Bachrein, S., Nurawan, A. (Eds.). Prosiding Seminar Nasional Pangan Fungsional Indigenous Indonesia: Potensi, Regulasi, Keamanan Efikasi dan Peluang Pasar; 2004. Bandung, Indonesia. Bogor (ID): Pusat Penelitian dan Pengembangan Sosial Ekonomi Pertanian.

Johan, M.E. 2005. Pengaruh tinggi pangkasan dan tinggi jendangan terhadap pertumbuhan dan hasil pucuk basah pada tanaman teh asal biji. Jurnal Penelitian Teh dan Kina. 8(1-2):43-48.

Junaedi, A., Susanto, S. 1996. Pengaruh hidrogen sianamida terhadap pertumbuhan dan produksi tanaman teh (Camellia sinensis (L.) O. Kuntze) setelah pemangkasan. Bul Agron. 24(1):1-5.

[PPTK] Pusat Penelitian Teh dan Kina. 2006. Petunjuk Kultur Teknis Tanaman Teh. Ed ke-3. Bandung (ID): Lembaga Riset Perkebunan Indonesia Pusat Penelitian Teh dan Kina Gambung.

Setyamidjaja, D. 2000. Budidaya dan Pengolahan Pasca Panen Tanaman Teh. Yogyakarta (ID): Kanisius.

Sriyadi, B. 2009. Seleksi pertumbuhan tunas klon teh harapan setelah pangkas. Jurnal Penelitian Teh dan Kina. 12(3):47-52.

Sukasman. 1988. Pemangkasan pada tanaman teh menghasilkan. Di dalam: Prosiding Seminar Pemangkasan Teh. Balai Penelitian Teh dan Kina Gambung. Bandung. Hal 49-64.

Suwardi, E. 1991. Penentuan saat pemangkasan pada tanaman teh menghasilkan (TM). Warta Teh dan Kina. 2(3-4):32-36.

Tobroni, M. 1990. Pemangkasan tanaman teh. In House Training Budidaya Tanaman Teh. Pusat Penelitian dan Pengembangan Perkebunan. Gambung.

Widayat, W., Johan, M.E. 2006. Kajian produksi teh tahun 2006 dan langkah pengamanannya tahun 2007. Warta Pusat Penelitian Teh dan Kina. 17(13):251-2. 